\title{
Romatolojik hastalıklarda tuzak nöropatileri: Cerrahi tedavi
}

\section{Entrapment neuropathies in rheumatologic diseases: Surgical intervention}

\section{Levent Küçük@}

Ege Üniversitesi Tıp Fakültesi Ortopedi ve Travmatoloji Anabilim Dalı, El Cerrahisi Bilim Dalı, İzmir Türkiye

Öz

Tuzak nöropatiler periferik sinirlerin anatomik yatkınlığın olduğu bölgelerde hasarlanması sonucu oluşan patolojilerdir. Romatolojik hastalarda tuzak nöropatiler toplumun diğer bireylerine göre daha fazla izlenmektedir. Bu hastaların önde gelen problemleri bilindiği gibi ağrı, duyu problemleri ve motor yetersizliktir. Özellikle motor yetersizlik durumunda cerrahi müdahale ile tedavi ön plana çıkmaktadır. Sinir dokusunun zor iyileşen bir doğaya sahip olduğu akılda tutularak motor kayıp yaşamadan yapılacak olan özenli cerrahiler yaşam kalitesini arttırır.

Anahtar Sözcükler: Median sinir, ulnar sinir, tibial sinir.

\begin{abstract}
Compression neuropathies are pathologies that result from damage to peripheral nerves in areas with anatomical predisposition. In rheumatologic patients, entrapment neuropathies are more common than other individuals in the community. The leading problems of these patients are pain, sensory problems and motor insufficiency. Especially in the case of motor insufficiency, surgical intervention comes to the forefront. Bearing in mind that the nerve tissue has a difficult healing nature, careful surgery before motor weakness improves the quality of life.
\end{abstract}

Keywords: Median nerve, ulnar nerve, tibial nerve.

\section{Giriş}

Tuzak nöropatiler periferik sinirlerin anatomik yatkınlığın olduğu bölgelerde hasarlanması sonucu oluşan patolojilerdir. Bu yatkınlık bölgeleri genellikle eklem çevresini kapsar. Tuzak nöropatiler sonrası oluşan sinir hasarı çeşitli tiplerde gözlenebilir. En sık karşımıza duyusal problemler ve ağrı şikâyeti ile gelse de motor etkilenmenin olduğu ve iş gücü kaybı ile sonuçlanabilecek daha ileri formları da karşımıza çıkabilmektedir. Periferik sinir tuzak nöropatilerinin toplumdaki prevalansı hiç de düşük değildir. Yalnızca karpal tünel sendromu prevalansının \%7 kadar tespit edildiği çalışmalar literatürde mevcuttur $(1,2)$.
Romatolojik hastalarda tuzak nöropatiler toplumun diğer bireylerine göre daha fazla izlenmektedir. Burada altta yatan tendon problemleri, sinoviyal hipertrofiler, eklem deformiteleri yatkınlığın olduğu bölgelerde sinirin tuzaklanmasına zemin hazırlamaktadır. Bu yazının amacı romatolojik hastalılarda rastladığımız tuzak nöropatilerin idiopatik nöropatilerden farklıığını ortaya koyup tanı ve tedavi aşamasında ipuçları vermek olacaktır.

Klinik pratikte en fazla karşılaşılan tuzak nöropatiler median sinirin el bileğinde tuzaklanması olan karpal tünel sendromu, ulnar sinirin dirsekte tuzaklanması olan kubital tünel sendromu, tibial sinirin ayak bileğinde tuzaklanması olan tarsal tünel sendromu ve tibial sinirin terminal dalının ayak önünde hasarlanması olan Morton nöromasıdır.

\footnotetext{
Sorumlu yazar: Levent Küçük

Ege Üniversitesi Tıp Fakültesi Ortopedi ve Travmatoloji Anabilim Dalı, El Cerrahisi Bilim Dalı, İzmir, Türkiye E-posta:kucuklevent@yahoo.com
} 


\section{Romatolojik hastalıklardaki tuzak nöropatilerin cerrahi tedavisi}

\section{I- Karpal Tünel Sendromu}

İdiopatik karpal tünel sendromunda genellikle hastalar gece uyuşması, daha sonra gündüz uyuşma ve ağrı gibi duyusal şikâyetlerin ön planda olduğu bir klinikle başvururlar. İdiopatik tipte çevre tendon ve eklem yapıları normaldir. Buna bağlı olarak ayırıcı tanıda çoğu zaman polinöropatiler, servikal disk hastalıkları ve ilgili sinirin diğer bölge tuzaklanmaları akla gelir. Romatizmal hastalıklarda gördüğümüz karpal tünel sendromunda ise motor bulgular daha şiddetli olabilir. İdiopatik karpal tünelden bir diğer farkı da çevre tendon ve eklemlerin işlevlerini çoğu zaman yerine getiremeyecek kadar deformiteye sahip olmasıdır. Motor bulguların önde olması romatizmal hastalıklarla birlikte görülen karpal tünel sendromunda ayırıcı tanıda motor nöron hastalıklarını ve tendon rüptürlerini de göz önünde bulundurmayı gerektirir.

Romatizmal el ve periferik sinir cerrahisi ile uğraşan bir hekim için ayrım güç olmasa da bu hastalık gruplarının birlikteliğini daha az sıklıkla tedavi eden hekimlerde tendon rüptürlerinin ayırıcı tanısını yapmak güç olabilir. Karpal tünel sendromunun motor bulgularında tenar bölge atrofisi ile beraber oppozisyonda güç kaybı ya da oppozisyon yapılamaması görülebilir. Romatizmal hastalıklarda en sık görülen tendon rüptürlerinin başında, ekstensör pollicis longus tendonunun distal radius dorsalinde Lister tuberkülü seviyesinde rüptüre olması gelir. Ekstensör pollicis longus tendonunun oppozisyona da kısmi destek vermesi sebebiyle bu tendon rüptürleri alışık olmayan gözler tarafından kolayca atlanabilir ya da karpal tünel sendromu bulgusu olarak değerlendirilebilir. Halbuki bu iki tanının tedavileri birbirinden farklıdır. Tendon rüptürü mekanik bir yetmezlik oluşturduğu için tendonun tamir edilmesi ya da tendon transferi ile oluşan fonksiyon kusurunun giderilmesi gerekir. Ekstensör pollicis longus tendon rüptüründe ekstensör indicis proprius tendonunun transferi oldukça tatminkâr sonuçlar vermektedir. Romatizmal hastalarda sıkça görülen diğer bir tendon hasarı ekstensör digitorum communis tendonlarına ait rüptürlerdir. $\mathrm{Bu}$ tendon rüptürleri dördüncü ekstensör kompartıman içerisinde distal radioulnar eklemden kaynaklanan deformitelere sekonder gözlenir. Dikkatli gözler tarafından kolaylıkla tanınabilse de elde hareket kısıtılığına yol açması karpal tünel sendromu ayırıcı tanısında kafa karıştırıcı olabilir. Ekstensör digitorum communis tendon rüptürleri uç uca greftli tamir ya da uç yan tendon transferleri ile tedavi edilir. Ekstensör digitorum communis rüptürünün altında yatan sebebin çoğunlukla distal radioulnar eklemde romatizmal hastalığa sekonder gelişmiş eklem yüzü bozuklukları, osteofitler ve bu osteofitlerin irritan etkisi ile tendonda kronik hasarlanma ile beraber rüptürlere yatkınlık olduğu akılda tutulmalıdır. Bu yüzden böyle bir tendon rüptürü ile karşılaşıldığında muayene ve direk grafi bulgularıyla distal radioulnar eklemin sağlıklı olup olmadığı belirlenmeli gerekirse tendon tamiri ya da transferi esnasında distal radioulnar ekleme yönelik cerrahi girişimler de eklenmelidir.

Daha az sıklıkta olsa da romatizmal hastalıklarda görülebilecek diğer bir tendon rüptürü fleksör pollicis longus rüptürüdür. Bu tendon başparmak oppozisiyonuna dolaylı katkı verdiği için oppozisyonda kuvvet azalmasına yol açabilir. Ama dikkatli muayene ile tendon hasarını, rüptürünü ortaya koyabilmek mümkündür. Fleksör pollicis longus tendon rüptürü tedavisinde greftli tendon tamirleri ya da tendon transferleri uygulanabilir.

Romatizmal hastalığı olan bireye tuzak nöropati teşhisi konduğunda bir ortopedik cerrah tarafından sorgulanan şey gerçekten cerrahi müdahale endikasyonu olup olmamasıdır. $\mathrm{Bu}$ hastaların önde gelen problemleri bilindiği gibi ağrı, duyu problemleri ve motor yetersizliktir. Özellikle motor yetersizlik durumunda cerrahi müdahale ile tedavi ön plana çıkmaktadır. Fakat sorgulanması gereken diğer bir husus yalnızca cerrahi gevşetmenin yeterli gelip gelmeyeceğidir. Periferik sinir hasarının tipi ve periferik sinirin nasıl iyileştiği temel bilgisine sahip olmadan bu iki soruya cevap vermek mümkün olmayacaktır. Sedon ve daha sonra Sunderland'ın yaptığı periferik sinir hasarına ait sınıflamalar, üzerinden her ne kadar uzun yıllar geçmiş olsa da hala güncelliklerini korumaktadırlar $(3,4)$. Çoğu sınıflama sisteminin elde edemediği prognozu ön görme, tedaviyi planlama gibi bir sınıflamadan beklenecek özellikleri taşımaları geçen bunca yıla rağmen hala güncel kalmalarını sağlamıştır. Bir cerrah için güç olan periferik sinir yaralanması, kompresyon nöropatisi ile karşılaşmış olan hastada sinir yaralanma tipinin Sedon'a göre nöropraksi mi, aksonotimesis mi olduğunu ayırt 
etmesidir. Nöropraksi bilindiği gibi fokal ileti bloğuyla seyreder ve aksonlar sağlamdır. Hemen her zaman gevşetme sonrası ya da konservatif tedavi ile iyi sonuç almak mümkündür. Fakat aksonotimesis aşamasında sinirde aksonal hasar vardır. Bu durumda sinire yapılacak olan gevşetme her zaman tam fonksiyonel sonuç vermeyebilir. Bu iki hasar tipinin tanı aşamasında anlaşılması ve hastaya cerrahi teklif ederken sinir iyileşmesi hakkında bilgi verilmesi çok önemlidir.

Konservatif tedavi ile kontrol altına alınamayan ağrı ve duyu problemleri varlığında cerrahi gevşetme önerilebilir. Hastada anamnez fizik muayene ya da elektromiyografi (EMG) ile motor tutulum tespit edildiğinde cerrahi müdahale ön plana çıkar. Motor yetersizliği tanımlamak için hastalar çoğunlukla "elimden küçük objeleri düşürmeye başladım", "elimde bir beceriksizlik gelişti" gibi ifadeler ile durumlarını anlatabilirler. Fizik muayenede ise motor yetersizliği ortaya koyacak en önemli bulgu hastaya 1. parmak pulpasını 5. parmak pulpasına doğru hareketlendirip sıkı bir şekilde tutmasını söylemek ve bu esnada tenar kasları palpe etmektir. Motor yetersizlik tespit edildiği an hasta cerrahi tedaviye yönlendirilmelidir. Bu sayede ileride gelişebilecek olan tenar kas atrofisinin de önüne geçilmiş olur. Çünkü atrofi geliştikten sonra yapılacak gevşetmeler hastanın fonksiyolarını düzeltmede yetersiz kalabilir. Cerrahi gevşetmede yapılan işlem transvers karpal ligamanın longitudinal kesilmesi ve böylelikle alttaki median sinire yarattığı baskının ortadan kaldırılmasındır. Farklı cerrahi yaklaşımlar bildirilmiştir. Endoskopik ya da açık cerrahi yöntemleri ile karpal tünel gevşetmesi yapılabilir. İdeal olan proksimalde el bileği volar cilt kıvrımını geçmeden, distalde Kaplan'ın kardinal çizgisinin distaline uzanmadan longitudinal cilt insizyonuyla girip, cilt altında önümüze çıkabilecek olan palmar kutanöz sinire zarar vermeden transvers karpal ligamanı boylu boyunca gevşetmektir (Şekil-1).

Transvers karpal ligaman gevşetmesi sonrasında gevşetmeye eklenebilecek bir takım ek müdahaleler mevcuttur. Bunlardan biri internal gevşetme denilen sinirin kendi fibröz kılıfının gevşetilmesidir. Fakat seçilmiş hastalarda yapılmaya gayret edilmeli, büyütme altında sinirin üzerinde herhangi bir fibröz bant tespit edilirse gevşetme yoluna gidilmelidir. İnternal nöroliz standart olarak cerrahiye eklenmemelidir. Çünkü internal gevşetme sırasında perinöryum ve epinöruma verilecek olan cerrahi travma bu bölgede fibrozise ve sinir dolaşımının bozulmasına neden olabilir. Romatizmal hastalığı olanlarda karpal tüne gevşetmesi sonrası eklenebilecek diğer bir cerrahi girişim eşlik eden fleksör tendonlara sinovektomi uygulanmasıdır.

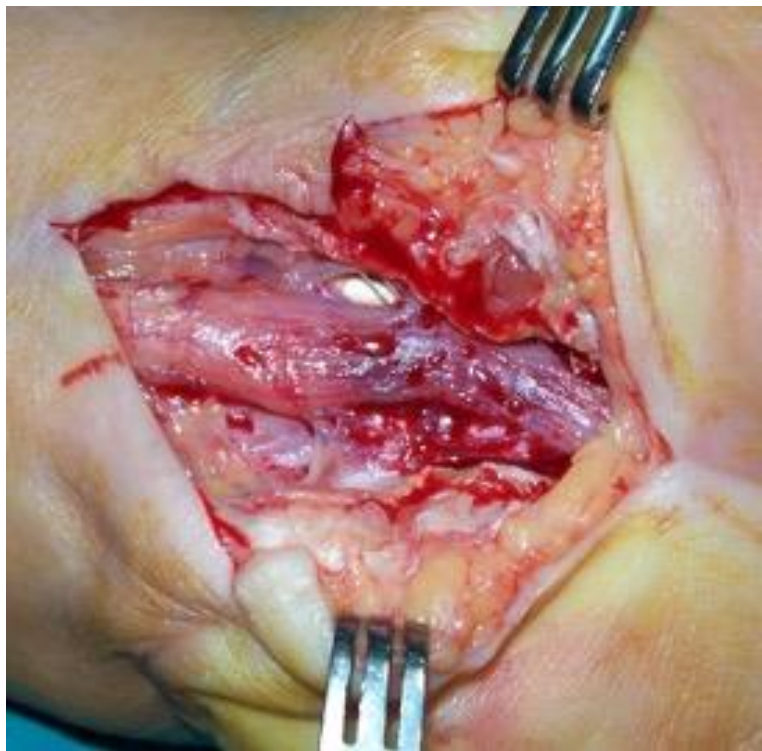

Şekil-1. Transvers karpal ligamanın gevşetilmesinden sonra kompresyona uğramış sinir bölgesindeki hiperemi görüntüsü.

Gevşetme sonrası yoğun bir sinoviyal doku siniri rahatsız ediyorsa sinovektomi gevşetmeye eklenebilir. Fakat bu da standart olarak her olguya uygulanmaya çalışılmamalı, gerçekten yoğun sinoviyal hipertrofi durumlarında uygulanmalıdır (Şekil-2). Özellikle daha önce opere olan olgularda bazen sinir dokusunun dolaşımıyla ilgili problemler olabilir. Bu durumda hipotenar yağ dokusundan hazırlanacak olan lokal flepler sinirin üzerine yerleştirilerek daha vasküler bir ortamda sinir dokusunu koruma amacı güdülür.

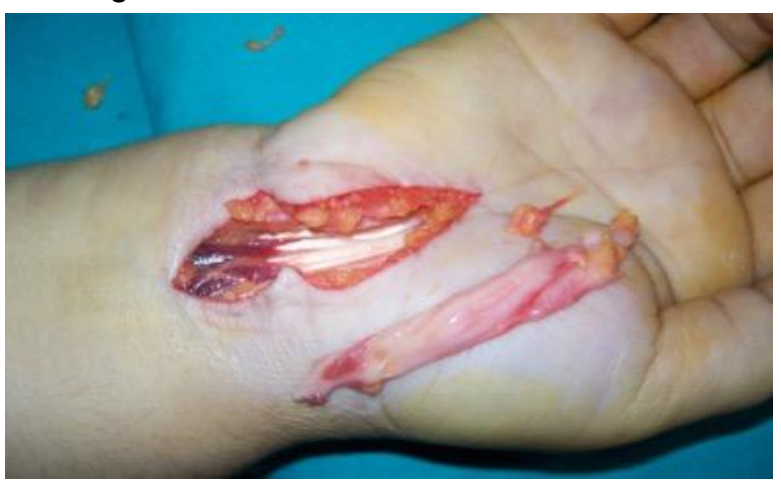

Şekil-2. Karpal tünel gevşetmesi sonrası eksize edilen sinoviya görüntüsü. 
Yalnızca transvers karpal ligaman gevşetmesinin yeterli fonksiyonel iyileşme sağlamayabileceğinin düşünüldüğü durumlarda oppozisyon gücünü artırmak için tendon transferleri gündeme gelir. $\mathrm{Bu}$ maksatla yapılan tendon transfer işlemine "oponensplasti" denir. Karpal tünel sendromunda rahatlıkla uygulanan opponensplasti yöntemlerinden bir tanesi Camits yöntemidir. Bu yöntemde palmaris longus tendonu, avuç içine uzanan bir insizyonla palmar fasya tendona dahil edilerek hazırlanır. Distal kısmı gevşetilir ve bir pulley oluşturularak farklı insersiyo yöntemlerinden birisi tercih edilerek başparmağa inserte edilir. Opponensplasti için kullanılabilecek diğer bir tendon, dördüncü parmağa uzanan fleksör digitorum superfisialis tendonudur. Fleksör digitorum superfisialis A2 pulley proksimalinden serbestleştirilip, karpal tünelden dışarı alınır. Sonrasında fleksör karpi ulnaris ya da psiform kemik etrafında oluşturulacak bir pulley yardımıyla etkin oppozisyon açısı ayarlanıp başparmağa inserte edilir. Oppozisyon amacıyla kullanılabilecek diğer donör kaslar ekstensör indicis proprius ile hipotenar kas grubudur.

\section{II- Kubital Tünel Sendromu}

Çoğu çalışmada üst ekstremitenin en sık gözlenen ikinci tuzak nöropatisi olarak adlandırılır. Bununla berbere özellikle dirseğin uzun süre aşırı fleksiyonda kaldığı durumlarda beşinci parmağında uyuşma, karıncalanma hissetmeyen yok gibidir. Romatizmal hastalıklarda dirsek ekleminde oluşabilecek kubitis valgus ya da fleksiyon kontraktürü gibi ekleme ait deformiteler ulnar sinir tuzaklanması için yatkınlık oluşturur. Yine romatizmal hastalıklarda görülebilecek ekleme ait sinovit ya da ganglion benzeri yer kaplayan oluşumlar da medial epikondil arkasında sinire baskı uygulayabilir ve kubital tünel sendromuna neden olabilir. Fakat çoğu zaman kubital tünel sendromunda net bir etiyolojik faktör tespit edilemez. Dirseğin uzun süre fleksiyonda kalması, önkol fleksör kaslarının abartılı aktivasyonuyla beraber fleksör karpi ulnarisin hipertfofisi suçlanan faktörler olmuşlardır. Dikkatli bir anamnez ve fizik muayene tanı için çoğu zaman yeterlidir. Anamnezde hastanın özellikle gece küçük parmağında uyuşma ve hissizlik şikayetinin olması elin intrensek kaslarının kuvvetsizliğini gösteren tırnak kesmede güçlük, kavrama zorluğu gibi şikayetlerinin olması olası bir ulnar sinir patolojisini düşündürür. $E M G$ sinir lezyonunun lokalizasyonu ve tuzaklanmanın şiddeti konusunda bize çok değerli bilgiler vermektedir (5). Kubital tünel sendromu tanısı koyduktan sonra sinir iyileşme özelliklerin hatırlayıp motor etkilenme olup olmadığını çok net ortaya koymak gerekir. Sinir iyileşmesinin yavaş olduğunu, sinir hasarı ve hedef organ arasındaki mesafenin sinir iyileşmesinden beklenen performansı ters orantılı olarak etkilediğini göz önünde bulundurmak gerekir. Konservatif tedavi yöntemleri ılımlı kubital tünel sendromu hastalarında tercih edilebilse de cerrahi sinir gevşetmeleri için karar vermede özellikle motor etkilenme şüphesi olduğunda geç kalınmamalıdır. Eldeki intrensek kaslarda oluşmuş atrofiden sonra yapılacak olan dirsek bölgesi ulnar sinir gevşetmeleri maalesef tam fonksiyonel geri dönüş sağlamayabilir.

Kubital tünel sendromu cerrahi müdahalesinde endoskopik ve açık cerrahi yöntemleri vardır (6). Temel olarak bu cerrahi yöntemler iki grupta incelenebilir. Birincisi yerinde gevşetme, ulnar sinirin medial intermusküler septumu delip posteriora çıktığı kol orta distal bölgesinden dirseğin posteriorunda medial epikondilin arkasından geçip fleksör karpi ulnaris kasının iki başı arasına girdiği alana kadar olan bölgede yerinde gevşetilmesi hala en sık tercih edilen yöntemdir (Şekil-3). Yerinde gevşetmeye ek olarak sinirin dirsek hareket aksının önüne taşınması ilave edilebilir. Öne taşıma cilt altına, fasya altına, kas altına olabilir. Yine bu bölgede medial epikondilin ulnar sinire irritasyon yapma özelliği tespit edilirse medial epikondilektomi de yapılabilir.

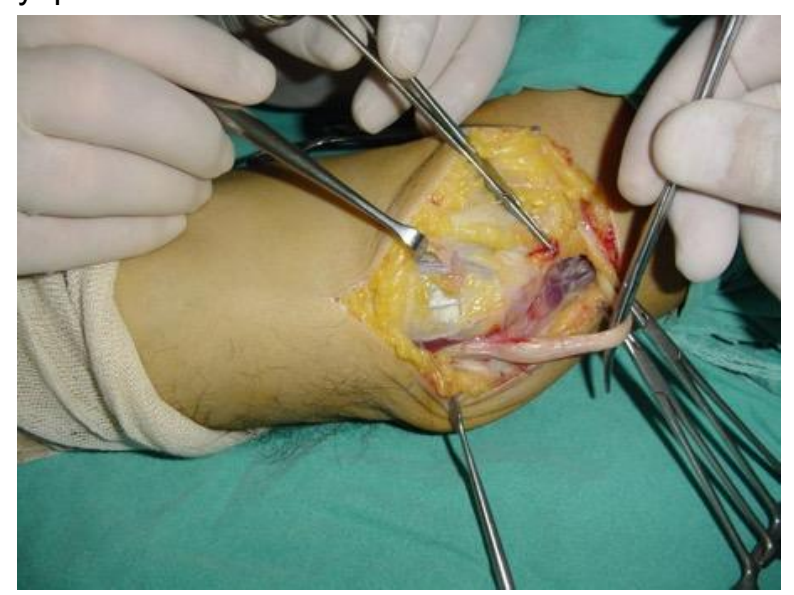

Şekil-3. Ulnar sinirin dirsek seviyesinde yerinde gevşetilmesinin görüntüsü. 


\section{III- Tarsal tünel sendromu}

Tibial sinirin medial malleol arkasında, ayak bileği fleksor retinakulumunun altında tuzaklanmasıdır. Alt ekstremiteye ait tuzak nöropatileri nispeten daha az görüldüğü için tanı koymayla ilgili zorluklar yaşanabilir. Özellikle ayak tabanına yayılan yanıcı batıcı tarzda nöropatik ağrısı olan romatolojik hastalarda tarsal tünel sendromu da ön tanıda akla gelmelidir. Fizik muayenede tibial sinir trasesi boyunca yapılan Tinel testinde kompresyonun olduğu bölgede pozitif sonuç alınır. Siniri germeye ve retinakulum altındaki hacmi azaltmaya yönelik bir provokatif test olan ayağı ekstensiyon-eversiyona zorlama hareketi, kompresyon nöropatisi olan hastalarda erken dönemde pozitif bulgu verir. Romatolojik hastalarda tarsal tünelin içerisinde eklemden ya da eşlik eden tendonlardan kaynaklanabilecek yer kaplayan oluşumların (gangliyon, tenosinovit gibi) da bulunabileceği hatırlanarak manyetik rezonans görüntüleme (MRI) ya da ultrason (USG) tetkiklerinin yapılması faydalı olur. Sinir hasarının derecesinin cerrahi sonrası sonuçları etkileyeceği akılda tutularak tanı aşamasında kompresyonun derecesi ve sinir hasarı tipi anlaşılmaya çalışılmalıdır.
IV- Morton nöromasI;

Tibial sinirin terminal dallarının özellikle üçüncü ve dördüncü metatars başları seviyesinde hasarlanması neticesinde oluşan bir nöromadır. Hastaların önde gelen şikâyeti özellikle dar ayakkabıyla ortaya çıkan parmaklara yayılan ayak tabanındaki ağrıdır. Fizik muayenede üçüncü ve dördüncü parmak arasında palpasyonla hassasiyet mevcuttur. Bu parmaklar arasında hipoestezi tespit edilebilir. Birinci ve beşinci metatars başları arasından tutup parmaklar sıkıştıııldığında ağrı genellikle agreve olur. Tanıda EMG ve MRI kullanılabilir. Geniş ayakkabı ile yaşamı tolere edemeyen ya da ayakkabı modifikasyonunun başarısız olduğu hasta grubunda cerrahi tedavi önerilir. Cerrahide dorsal insizyonla girilip intermetatarsal bağ gevşetilir altındaki nöromaya ulaşılır ve eksize edilir. Ayak tabanından herhangi bir insizyon yapılmaz. Ayak tabanında oluşacak olan hipertofik skar postoperatif dönemde ciddi basış bozukluklarıyla sonuçlanabilir.

Sonuç olarak romatolojik hastalarda olası periferik sinir kompresyon nöropatilerinde tanı ve tedavi planlamasında fizik muayene en önemli yeri alır. Sinir dokusunun zor iyileşen bir doğaya sahip olduğu akılda tutularak motor kayıp yaşamadan yapılacak olan özenli cerrahiler yaşam kalitesini arttırır.

\section{Kaynaklar}

1. Thoma A, Veltri K, Haines T, Duku E. A meta-analysis of randomized controlled trials comparing endoscopic and open carpal tunnel decompression. Plast Reconstr Surg 2004; 114 (5): 1137-46.

2. Ferry S, Pritchard T, Keenan J, Croft P, Silman AJ. Estimating the prevalence of delayed median median nerve cunduction in the general population. Br J Rheumatol 1998; 37 (6): 630-5.

3. Sunderland S. Nerves and nerve injuries. 2nd ed. London: Churchill Livingstone; 1978.p.1-13.

4. Ozaksar K, Gunay H, Kucuk L, Coskunol E. Long-term results of primary repair of combined cuts on the median and ulnar nerves in the forearm. Ulus Travma Acil Cerrahi Derg 2017; 23 (5): 410-14.

5. Yalcinkaya S, Atamaz FC, Ozdemir O, Kucuk L, Gunay H, On AY. The value of short segment conduction studies in localizing ulnar neuropathy of the elbow. Hand Microsurg. 2017; 6 (2): 68-74.

6. Gurbuz Y, Kucuk L, Yalcinkaya S, Ozaksar K, Ozdemir O. Comparative outcomes of in situ decompression and anterior transposition in McGowan stages II-III of cubital tunnel syndrome. Hand Microsurg 2017; 6: 21-7. 